\title{
Dermal fibroblast transcriptome indicates contribution of WNT signaling pathways in the pathogenesis of Apert syndrome
}

\author{
Arda Çetinkaya ${ }^{1,2}$, Ekim Taşkıran² ${ }^{2}$ Tutku Soyer ${ }^{3}$, Pelin Özlem Şimşek-Kiper ${ }^{4}$, Gülen Eda \\ Utine $^{4}$, Gökhan Tunçbilek ${ }^{5}$, Koray Boduroğlu', Mehmet Alikaşifoğlu² \\ ${ }^{1}$ Medical Genetics Unit, Zeynep Kamil Women and Children's Training and Research Hospital, İstanbul, Turkey; Department \\ of ${ }^{2}$ Medical Genetics, ${ }^{3}$ Pediatric Surgery, ${ }^{4}$ Pediatric Genetics and ${ }^{5}$ Plastic Reconstructive and Aesthetic Surgery, Faculty of \\ Medicine, Hacettepe University, Ankara, Turkey.E-mail: ardabiochem@yahoo.com
}

Received: 13th March 2018, Revised: 19th April 2018, Accepted: 24th April 2018

SUMMARY: Çetinkaya A, Taşkıran E, Soyer T, Şimşek-Kiper PÖ, Utine GE, Tunçbilek G, Boduroğlu K, Alikaşifoğlu M. Dermal fibroblast transcriptome indicates contribution of WNT signaling pathways in the pathogenesis of Apert syndrome. Turk J Pediatr 2017; 59: 619-624.

Cranial sutures are unossified connective tissue structures between the cranial bones, which allow expansion of these bones during development. Premature ossification of these structures is called craniosynostosis. Apert syndrome is a well-defined genetic syndrome, which is characterized by craniosynostosis and arises as a result of two missense mutations in Fibroblast Growth Factor Receptor, type 2 gene (FGFR2). In this study, differentially expressed genes in dermal fibroblasts from individuals with Apert syndrome and controls were investigated to identify important pathways in the pathogenesis of Apert syndrome. For this purpose, primary skin fibroblast cultures obtained from 3 individuals with Apert syndrome and 3 controls without craniosynostosis were compared by transcriptome microarray, GeneChip Human Genome U133 Plus 2.0. As a result, 181 genes were shown to be differentially expressed between experimental groups. Among these, 10 genes, which significantly differ in Apert syndrome fibroblasts compared to controls, were shown to be involved in a common interaction network and have common Gene ontology (GO) biological processes terms. COL11A1, COMP, CPXM2, ITGA8, MGF and TNC are differentially expressed genes that have GO terms associated with extracellular matrix (ECM) organization, while FRZB, SFRP2 and WNT2 are involved in WNT signaling pathway. Reorganization of ECM and changes in WNT signaling pathway show that Apert syndrome primary fibroblast cultures may have an increased potential for bone differentiation. The results of this study support craniosynostosis in Apert syndrome may be the result of fast and early differentiation of connective tissue along the sutures.

Key words: craniosynostosis, Apert syndrome, fibroblast growth factor receptor type 2, transcriptome, fibroblast.

Craniosynostosis is the premature ossification of sutures, which lies between neurocranial bones and is seen in about $1 / 1500-1 / 2500$ newborns. ${ }^{1-5}$ Cranial sutures, which are made up of connective tissue, ossifies with age and forms interlocked immovable joints connecting cranial bones. ${ }^{6}$ Craniosynostosis may lead to major and potentially debilitating health problems such as increased intracranial pressure, vision and hearing loss due to compression of cranial nerves, and sleep apnea. ${ }^{7}$

Among the several causes of craniosynostosis, some arise primarily as the dysregulation of

This work is based on Medical Genetics Specialty Training Thesis "Çetinkaya A. Transcriptome study in primary fibroblast cultures in craniosynostosis. Hacettepe University, Faculty of Medicine, Ankara, 2014", and was presented as a poster in the $11^{\text {th }}$ National Medical Genetics Congress in 2014 organized by Turkish Society of Medical Genetics. 
the cranial sutures, while some are secondary to the disturbance of cranial enlargement and development, such as brain injury and primary microcephaly syndromes. ${ }^{3}$ Primary craniosynostosis can be either isolated or arise as part of a syndrome, which are associated with genetic disorders. More than 200 genetic disorders that include chromosomal abnormalities, copy number variations and single gene disorders have been associated with craniosynostosis. ${ }^{8}$

Apert syndrome (MIM101200) is a sporadic or autosomal dominantly inherited well-recognized disorder. It is characterized by primary craniosynostosis, other skeletal anomalies, osseous/cutaneous syndactyly, dysmorphic findings such as midface hypoplasia, as well as other less common systemic anomalies, such as congenital heart defects. Two missense mutations (p.Ser252Trp and p.Pro253Arg) in Fibroblast Growth Factor Receptor 2 gene (FGFR2), which result in ligand-dependent gain-of-function, are responsible for $98 \%$ of Apert syndrome in affected individuals. ${ }^{2}$ Similarly, $>90 \%$ of mutation prevalence for these mutations is observed in Turkish population. ${ }^{9}$ Other FGFR2 mutations and mutations in FGF/FGFR genes are also associated with craniosynostosis-related syndromes like Muenke syndrome, Crouzon syndrome and Pfeiffer syndrome, indicating the importance of fibroblast growth factor receptors (FGFRs) and its ligands, fibroblast growth factors (FGFs), in the genetic etiology of craniosynostosis. ${ }^{2}, 10$

The main role of FGFRs in cranial sutures is to oversee gene expression in sutural cells to regulate osteoblastic cell differentiation and stem cell proliferation. ${ }^{11,12}$ In this study, we investigated the transcriptome profiles of cultured primary dermal fibroblasts from individuals with Apert syndrome and controls to identify differentially expressed genes (DEGs) to search for pathways dysregulated in the pathogenesis of craniosynostosis.

\section{Material and Methods}

\section{Participants}

Three children with clinical findings of Apert syndrome and 3 children with no apparent genetic disorders, selected as the control group, with ages ranging between 2.5 and 10 years were enrolled in the study. Physical examination was performed in each individual to note the dysmorphic findings and exclude the presence of a skin disorder. Peripheral blood samples and gluteal skin biopsies gathered by punch biopsy of the skin under $2 \mathrm{mg} / \mathrm{ml}$ lidocaine anesthesia and were obtained from each individual with Apert syndrome, while abdominal skin biopsies were obtained from individuals with no apparent genetic disorders undergoing surgery for an unrelated intraabdominal disease. Informed consents were obtained from parents of all children for participating in the study. This study was reviewed and approved by the Non-Interventional Clinical Research Ethics Board of Hacettepe University (TBK 12/07).

\section{FGFR2 Sequence Analysis}

DNA was obtained from peripheral blood leukocytes in 3 children with Apert syndrome by ammonium acetate precipitation. Sanger DNA sequencing of Exon 7 of FGFR2 (ENST00000358487) was performed by using BigDye Terminator Cycle Sequencing kit (Applied Biosystems, USA) and primers 5' -TGACA GCCCTCTGGACAAC-3' and 5'-TCATCCTCTCTCAACTCCAACA-3' in order to demonstrate the mutations responsible for Apert syndrome. ${ }^{13}$

\section{Primary Dermal Fibroblast Cultures}

Primary dermal fibroblasts were grown in DMEM containing $1 \%$ L-Glutamine, $1 \%$ Penicillin/ streptomycin, $0.2 \%$ Gentamycin, $10 \%$ fetal bovine serum after careful removal of epidermal layer to avoid keratinocyte contamination. Penicillin, streptomycin, Gentamycin and fetal bovine serum were removed from culture media and cells were grown either in absence or presence of 2nM FGF2 for 48 hours thus, forming 4 experimental groups (Apert syndrome 0pM (picomolars) FGF2, Apert syndrome 2000pM FGF2, Control 0pM FGF2, Control 2000pM FGF2). FGF2 concentration was used as determined in previous studies. ${ }^{14,15}$

\section{RNA isolation and Microarray for Transcriptome}

Total RNA from primary dermal fibroblast cultures were isolated by using TRIzol (Sigma-Aldrich, Germany) as suggested by the manufacturer. GeneChip ${ }^{\circledR}$ Human Genome U133 Plus 2.0 Array (Affymetrix, USA) was utilized to determine transcription profiles of each sample according to protocols provided 
by the manufacturer. Microarrays were scanned by GeneChip ${ }^{\circledR} 3000$ Scanner (Affymetrix, USA). Affymetrix Expression Console using MAS 5.0 (Microarray Suite 5.0) protocol and $\mathrm{R}$ x64 v3.1.0 with affy and limma modules were used to compare gene expression levels between experimental groups. ${ }^{16}$ Differentially expressed genes (DEGs) with greater than 1.5 times difference in logarithmic scale between groups and with a t-test value $\mathrm{p}>0.05$ were considered statistically significant results. No further experiments were carried out to evaluate transcriptome microarray results. DEGs were evaluated for common gene ontology (GO) terms by using STRING (Search Tool for the Retrieval of Interacting Genes/Proteins). ${ }^{17}$

\section{Results}

\section{Clinical Findings and Mutation Analysis}

Three female individuals with Apert syndrome (A1, A2, A3) were similarly affected and shared common features of the disorder (Table I). Individual A2 differed from others in having cleft lip and individual A3 had atrial septal defect. Individuals A1 and A3 were heterozygous for c.934C $>$ G (p.Ser252Trp), while A2 was heterozygous for c.937C $>$ G (p.Pro253Arg). On the other hand, three individuals in control group $(\mathrm{C} 1, \mathrm{C} 2, \mathrm{C} 3)$ did not present with any dysmorphic features of the syndrome (Table I).

\section{Transcriptome Analysis}

In order to detect the possible effect of the substrate FGF2 on transcription in fibroblasts from Apert syndrome and control groups 4 experimental groups were formed (Apert syndrome 0pM FGF2, Apert syndrome 2000pM FGF2, Control 0pM FGF2, Control 2000pM FGF2). These experimental groups were compared in pairs and a total of 181 transcripts were identified as DEGs in at least one pair (Table II). STRING identified 90 associations between 71 of these genes which is statistically significant $\left(\mathrm{p}=2.58 \times 10^{-11}\right)$. These associations are clumped into 2 large clusters, containing 41 genes (Cluster I) and 14 genes (Cluster II) (Fig. 1).

DEGs detected in these comparisons are also enriched for GO biological processes (Table III). The significantly enriched terms are extracellular matrix (ECM) organization, cell adhesion and mesenchyme development. 33 of

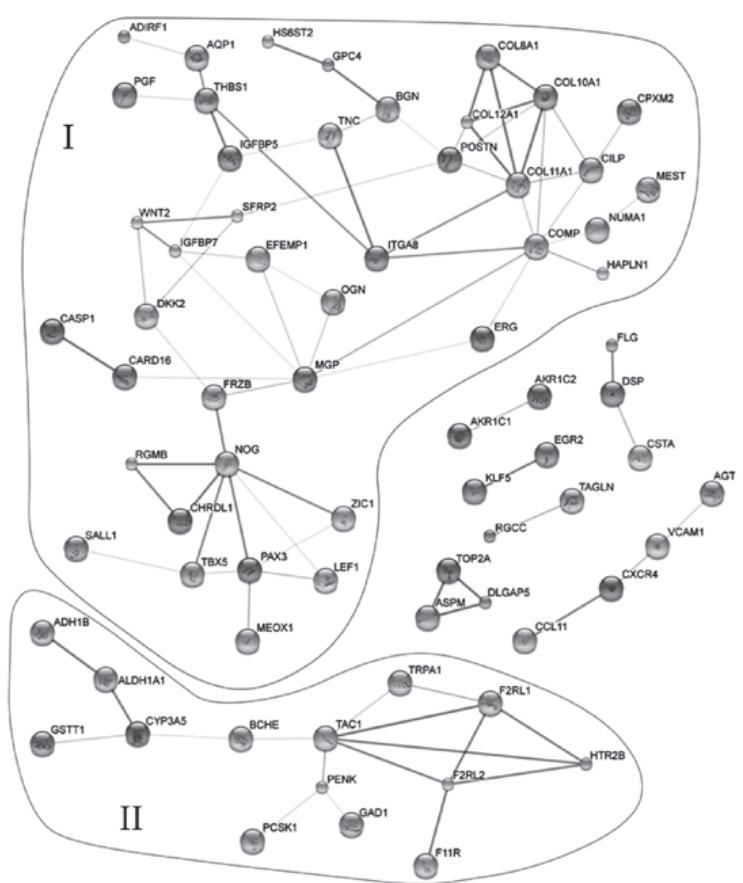

Fig. 1. Association of DEGs in STRING, showing 2 large association clusters.

*Note that the thickness of lines joining nodes of genes represents the strength of association.

the 65 DEGs associated with these biological processes appear in a common interaction network in cluster I. Among these 10 are DEGs that arise when non-FGF2 treated Apert syndrome and control fibroblast trancriptomes are compared - COL11A1, COMP, MGF, SFRP2, WNT2 are upregulated in Apert syndrome fibroblasts, while CPXM2, FRZB, ITGA8, TBX5, TNC are down regulated. COL11A1, COMP, CPXM2, ITGA8, MGF, TNC are involved in ECM organization according to associated GO terms, while FRZB, SFRP2, WNT2 are components of the WNT signaling pathway. ${ }^{18}$

\section{Discussion}

Apert syndrome is one of the oldest known syndromes associated with craniosyostosis, however the pathogenesis of this syndrome is still unclear. Missense mutations in FGFR2 causes Apert syndrome and leads to increased ligand-dependent FGFR2 signaling activating intracellular signaling pathways that regulate gene expression. ${ }^{19}$

In this study, we focused on the DEGs in nonFGF2-treated fibroblasts from individuals with Apert syndrome and control groups, and found that 2 biological processes, ECM organization 
Table I. Clinical Features of Individuals with Apert Syndrome (A1, A2, A3) and Those in The Control Group (C1, C23, C3).

\begin{tabular}{|c|c|c|c|c|c|c|}
\hline Individuals & A1 & $\mathrm{A} 2$ & A3 & $\mathrm{C} 1$ & $\mathrm{C} 2$ & $\mathrm{C} 3$ \\
\hline Age & 8 & 7 & 2.5 & 6 & 7 & 10 \\
\hline Gender & $\mathrm{F}$ & F & $\mathrm{F}$ & $\mathrm{F}$ & $\mathrm{F}$ & $\mathrm{F}$ \\
\hline Craniosynostosis & Coronal & Coronal & Coronal & - & - & - \\
\hline Biparietal diameter & NFA & NFA & NFA & NFA & NFA & NFA \\
\hline Height & NFA & NFA & NFA & NFA & NFA & NFA \\
\hline Intellectual disability & - & Mild & - & - & - & - \\
\hline $\begin{array}{l}\text { Increased } \\
\text { intracranial pressure }\end{array}$ & - & - & - & - & - & - \\
\hline Proptosis & + & + & + & - & - & - \\
\hline Hypertelorism & + & + & + & - & - & - \\
\hline Visual loss & - & - & - & - & - & - \\
\hline Hearing loss & - & - & - & - & - & - \\
\hline Mid-facial hypoplasia & + & + & + & - & - & - \\
\hline Dysmorphic nose & + & + & + & - & - & - \\
\hline Cleft lip & - & + & - & - & - & - \\
\hline $\begin{array}{l}\text { Congenital heart } \\
\text { disease }\end{array}$ & - & - & ASD & - & - & - \\
\hline Hallux valgus & + & + & + & - & - & - \\
\hline Broad thumbs & + & + & + & - & - & - \\
\hline Brachy-syndactyly & + & + & + & - & - & - \\
\hline Treatment & $\begin{array}{l}\text { Cranioplasty, } \\
\text { Syndactyly } \\
\text { repair }\end{array}$ & $\begin{array}{l}\text { Cranioplasty, } \\
\text { Syndactyly } \\
\text { repair }\end{array}$ & $\begin{array}{l}\text { Cranioplasty, } \\
\text { Syndactyly } \\
\text { repair }\end{array}$ & - & - & - \\
\hline FGFR2 Mutation & p.Ser252Trp & p.Pro253Arg & p.Ser252Trp & & & \\
\hline Family History & - & - & - & - & - & - \\
\hline
\end{tabular}

F: female; M: male; NFA: normal for age; ASD: atrial septal defect

and mesenchyme differentiation, arise as the major pathways dysregulated. These pathways play a role in bone formation and osseous differentiation.

ECM related genes detected in this study include COL11A1, COMP, CPXM2, ITGA8, $M G F$ and TNC. Among these genes COL11A1 along with COL1OA1, another upregulated transcript shown in this study, encodes for collagens expressed in skeletal tissues which is upregulated in differentiating chondroblasts and osteoblasts. ${ }^{20,21}$ Another ECM protein COMP, which is shown to be upregulated in this study, captures Bone Morphogenic Protein 2 (BMP2) and leads to a localized increase in its concentration, promoting bone differentiation. ${ }^{22}$ In contrast to these 2 transcripts, downregulation of MGP is associated with abnormal tissue calcification in mice and men. 23,24 This transcript is upregulated in Apert syndrome fibroblasts which may compensate for increased tendency towards osseous differentiation.

FRZB, SFRP2, WNT2, which are 3 of the most pronounced mesenchyme differentiation related genes in this study, indicate changes in WNT pathway in fibroblasts obtained from individuals with Apert syndrome. This is a significant finding because upregulation of WNT signaling leads to craniosynostosis in mice. ${ }^{25}$ A study in support of the importance of WNT2 and SFRP proteins shows that these genes are upregulated in coronal sutures of individuals with non-syndromic craniosynostosis. ${ }^{26}$ In addition, the balance between WNT and FGF signaling pathways is important in normal limb 
Table II. Paired Comparisons of 4 Experimental Groups to Identify DEGs.

\begin{tabular}{llll}
\hline Compared experimental groups & $\begin{array}{l}\text { Increased } \\
\text { expression }\end{array}$ & $\begin{array}{l}\text { Decreased } \\
\text { expression }\end{array}$ & Total \\
\hline $\begin{array}{l}\text { Apert Syndrome 0pM FGF2 - } \\
\text { Control 0pM FGF2 }\end{array}$ & 32 & 28 & 60 \\
$\begin{array}{l}\text { Apert Syndrome 2000pM FGF2 - } \\
\text { Control 2000pM FGF2 }\end{array}$ & 23 & 38 & 61 \\
$\begin{array}{l}\text { Apert Syndrome 2000pM FGF2 - } \\
\text { Apert Syndrome 0pM FGF2 }\end{array}$ & 13 & 94 & 107 \\
$\begin{array}{l}\text { Control 2000pM FGF2 - } \\
\text { Control 0pM FGF2 }\end{array}$ & 11 & 11 & 22 \\
\hline
\end{tabular}

Table III. GO Terms for Biological Processes That 181 DEGs Are Enriched for Detected By STRING (DEGs In Cluster I Are Underlined).

\begin{tabular}{|c|c|c|}
\hline GO Terms & $p$ value & Genes \\
\hline $\begin{array}{l}\text { Extracellular Matrix } \\
\text { Organization }\end{array}$ & $5.15 \times 10^{-10}$ & $\begin{array}{l}\text { A2M, ADAMTS5, EGFL6, FKBP1A, LOXL2, NTN4, PLOD2, } \\
\text { TLL2, F11R, AGT, VCAM1, BGN, COL8A1, COL10A1, } \\
\text { COL11A1, COL12A1, COMP, EFEMP1, HAPLN1, ITGA8, } \\
\underline{\text { POSTN, SFRP2, THBS1, TNC }}\end{array}$ \\
\hline Cell Adhesion & $1.06 \times 10^{-11}$ & 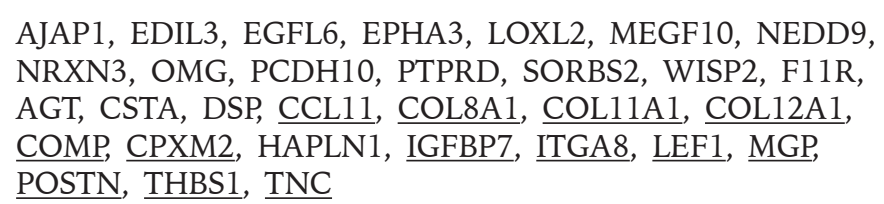 \\
\hline $\begin{array}{l}\text { Mesenchyme } \\
\text { Development }\end{array}$ & $6.05 \times 10^{-4}$ & $\begin{array}{l}\text { LOXL2, LOXL3, HTR2B, FRZB, LEF1, NOG, PAX3, THBS1, } \\
\text { TBX5, WNT2 }\end{array}$ \\
\hline
\end{tabular}

development. ${ }^{27}$ A loss of balance between the 2 pathways as shown in dermal fibroblasts here may contribute to the pathogenesis of limb abnormalities in Apert syndrome. The emergence of changes in WNT pathway at gene regulation level is important as, to our knowledge, this has not been reported previously in transcriptome studies for Apert syndrome. $5,15,28-30$

The effect of FGF2 addition to the culture media for fibroblasts from individuals with Apert syndrome and control groups is hard to evaluate as minimal variation occurs with the addition of FGF2 (data not shown). However, it is interesting to note that FGF2 results in upregulation of NOG for which heterozygous loss-of-function mutations are associated with multiple synostoses syndrome type 1 , while FGF2 addition does not significantly affect NOG expression in control fibroblasts, indicating the potential sensitivity of Apert syndrome fibroblasts. ${ }^{31}$ In this study, only a single concentration of FGF is tested, and a more pronounced response in gene expression by higher concentrations of FGF cannot be excluded.

In conclusion, we have shown that Apert dermal fibroblasts have gene expression profiles indicative of changes in WNT signaling and reorganization of ECM which may suggest a tendency towards increased osseous differentiation. The results of this study must be tested in larger study groups and supported by functional analyses. Also, the biological significance of the results must be tested in in vivo experiments.

\section{Acknowledgement}

We are indebted to the families for their kind participation in the study. We thank Dilek Özdağ $(\mathrm{MsC})$ for her contribution in the establishment and follow-up of primary fibroblast cultures and Burak Öztürk for his assistance in obtaining tissue samples. This work is supported by a grant from the Hacettepe University Research Fund, 012 D12 103001. 


\section{REFERENCES}

1. Johnson D, Wilkie AO. Craniosynostosis. Eur J Hum Genet 2011; 19: 369-376.

2. Kimonis V, Gold JA, Hoffman TL, Panchal J, Boyadjiev SA. Genetics of craniosynostosis. Semin Pediatr Neurol 2007; 14: 150-161.

3. Nagaraja S, Anslow P, Winter B. Craniosynostosis. Clin Radiol 2013; 68: 284-292.

4. Levi B, Wan DC, Wong VW, Nelson E, Hyun J, Longaker MT. Cranial suture biology: from pathways to patient care. J Craniofac Surg 2012; 23: 13-19.

5. Coussens AK, Wilkinson CR, Hughes IP, et al. Unravelling the molecular control of calvarial suture fusion in children with craniosynostosis. BMC Genomics 2007; 8: 458.

6. Opperman LA. Cranial sutures as intramembranous bone growth sites. Dev Dyn 2000; 219: 472-485.

7. Wan DC, Kwan MD, Lorenz HP, Longaker MT. Current treatment of craniosynostosis and future therapeutic directions. Front Oral Biol 2008; 12: 209-230.

8. Cunningham ML, Seto ML, Ratisoontorn C, Heike CL, Hing AV. Syndromic craniosynostosis: from history to hydrogen bonds. Orthod Craniofac Res 2007; 10: 67-81.

9. Nur BG, Pehlivanoglu S, Mihci E, et al. Clinicogenetic study of Turkish patients with syndromic craniosynostosis and literature review. Pediatr Neurol 2014; 50: 482-490.

10. Lajeunie E, Le Merrer M, Bonaiti-Pellie C, Marchac D, Renier D. Genetic study of nonsyndromic coronal craniosynostosis. Am J Med Genet 1995; 55: 500-504.

11. Chim H, Manjila S, Cohen AR, Gosain AK. Molecular signaling in pathogenesis of craniosynostosis: the role of fibroblast growth factor and transforming growth factor-beta. Neurosurg Focus 2011; 31: E7.

12. Ang BU, Spivak RM, Nah HD, Kirschner RE. Dura in the pathogenesis of syndromic craniosynostosis: fibroblast growth factor receptor 2 mutations in dural cells promote osteogenic proliferation and differentiation of osteoblasts. J Craniofac Surg 2010; 21: $462-467$

13. Zerbino DR, Achuthan P, Akanni W, et al. Ensembl 2018. Nucleic Acids Res (Accessed December 2017).

14. Yu K, Herr AB, Waksman G, Ornitz DM. Loss of fibroblast growth factor receptor 2 ligand-binding specificity in Apert syndrome. Proc Natl Acad Sci U S A 2000; 97: 14536-14541.

15. Yeh E, Fanganiello RD, Sunaga DY, et al. Novel molecular pathways elicited by mutant FGFR2 may account for brain abnormalities in Apert syndrome. PLoS One 2013; 8: e60439.

16. Smyth GK. Linear models and empirical bayes methods for assessing differential expression in microarray experiments. Stat Appl Genet Mol Biol 2004; 3: Article3.

17. Jensen LJ, Kuhn M, Stark M, et al. STRING 8--a global view on proteins and their functional interactions in 630 organisms. Nucleic Acids Res 2009; 37: D412-D416.
18. Bovolenta P, Esteve P, Ruiz JM, Cisneros E, Lopez-Rios J. Beyond Wnt inhibition: new functions of secreted Frizzled-related proteins in development and disease. J Cell Sci 2008; 121: 737-746.

19. Ibrahimi OA, Zhang F, Eliseenkova AV, Itoh N, Linhardt RJ, Mohammadi M. Biochemical analysis of pathogenic ligand-dependent FGFR2 mutations suggests distinct pathophysiological mechanisms for craniofacial and limb abnormalities. Hum Mol Genet 2004; 13: 23132324.

20. Felimban R, Ye K, Traianedes K, et al. Differentiation of stem cells from human infrapatellar fat pad: characterization of cells undergoing chondrogenesis. Tissue Eng Part A 2014; 20: 2213-2223.

21. Zheng Q, Zhou G, Morello R, Chen Y, Garcia-Rojas $\mathrm{X}$, Lee B. Type $\mathrm{X}$ collagen gene regulation by Runx2 contributes directly to its hypertrophic chondrocytespecific expression in vivo. J Cell Biol 2003; 162: 833-842.

22. Ishida K, Acharya C, Christiansen BA, Yik JH, DiCesare PE, Haudenschild DR. Cartilage oligomeric matrix protein enhances osteogenesis by directly binding and activating bone morphogenetic protein-2. Bone 2013; 55: 23-35.

23. Munroe PB, Olgunturk RO, Fryns JP, et al. Mutations in the gene encoding the human matrix Gla protein cause Keutel syndrome. Nat Genet 1999; 21: 142-144.

24. Speer MY, McKee MD, Guldberg RE, et al. Inactivation of the osteopontin gene enhances vascular calcification of matrix Gla protein-deficient mice: evidence for osteopontin as an inducible inhibitor of vascular calcification in vivo. J Exp Med 2002; 196: 1047-1055.

25. Yu HM, Jerchow B, Sheu TJ, et al. The role of Axin2 in calvarial morphogenesis and craniosynostosis. Development 2005; 132: 1995-2005.

26. Stamper BD, Park SS, Beyer RP, et al. Differential expression of extracellular matrix-mediated pathways in single-suture craniosynostosis. PLoS One 2011; 6: e26557.

27. ten Berge D, Brugmann SA, Helms JA, Nusse R. Wnt and FGF signals interact to coordinate growth with cell fate specification during limb development. Development 2008; 135: 3247-3257.

28. Bochukova EG, Soneji S, Wall SA, Wilkie AO. Scalp fibroblasts have a shared expression profile in monogenic craniosynostosis. J Med Genet 2010; 47: 803-808.

29. Fanganiello RD, Sertie AL, Reis EM, et al. Apert p.Ser252Trp mutation in FGFR2 alters osteogenic potential and gene expression of cranial periosteal cells. Mol Med 2007; 13: 422-442.

30. Carinci F, Bodo M, Tosi L, et al. Expression profiles of craniosynostosis-derived fibroblasts. Mol Med 2002; 8: $638-644$

31. Gong Y, Krakow D, Marcelino J, et al. Heterozygous mutations in the gene encoding noggin affect human joint morphogenesis. Nat Genet 1999; 21: 302-304. 